http://jmscr.igmpublication.org/home/ ISSN (e)-2347-176x ISSN (p) 2455-0450 crossref DOI: https://dx.doi.org/10.18535/jmscr/v7i8.139

Journal Of Medical Science And Clinical Research

\title{
Geriatric Post-Operative Delirium, A Rarely Reported Common Entity
}

\author{
Authors \\ Prajwala S Kaushik ${ }^{1 *}$, Pallavi Waghalkar ${ }^{2}$ \\ ${ }^{1}$ Assistant Professor, Dept of Anesthesia, GGMC and JJ hospital \\ ${ }^{2}$ Associate Professor, Dept of Anesthesia, Seth GSMC, KEM hospital \\ *Corresponding Author \\ Prajwala S Kaushik \\ Assistant Professor, Dept of Anesthesia, GGMC and JJ hospital
}

\begin{abstract}
Delirium an acutely altered and fluctuating mental status has been a common occurance in the elderly in the post-operative period. Despite this, there have been few studies or cases reported in India. The objective of this case report is to sensitize the medical fraternity towards this condition and its importance.

We report a case of a 70 year old male who developed signs and symptoms suggestive of delirium after a spine surgery. We herebydiscuss the risks, predisposing and precipitating factors, diagnostic methods, preventive measures and treatment strategies of the condition.

With an increase in ageing population, post op delirium no longer remains a concern only for the developed nations and hence necessitates a watchful eye.

Keywords: Post-operative delirium, elderly, India.
\end{abstract}

\section{Introduction}

Delirium is defined as an acutely altered and fluctuating mental status with features of inattention and an altered level of consciousness. ${ }^{(1)}$ This may be accompanied by hallucinations or cognitive symptoms such as disorientation or temporary memory dysfunction. It could manifest as a hyperactive, hypoactive or a mixed form.

Delirium developed in the post-surgical period is associated with poor outcomes including functional decline, longer hospitalization, greater costs and higher mortality. ${ }^{(2)}$ Its incidence ranges from $9 \%$ to $87 \%$ and is more common in the elderly.

The percentage of geriatric population in India has increased by 35 percent from 2001 to $2011^{(3)}$. Hence the number of geriatric patients undergoing surgery has also increased. Despite post-operative delirium being a common occurrence, there have been few studies or cases reported in India. So it is prudent to be aware of the risk factors, preventive measures and treatment of this condition.

\section{Case Report}

A 78 year old hypertensive male presented with bilateral lower limb weakness and was diagnosed with compressive cervical myelopathy. He was posted for decompression and fixation of cervical and lumbar regions. Patient had no significant past medical or surgical history. He was a chronic smoker and alcoholic. He was found to be hard on hearing. Clinical examination and all biochemical investigations were normal. After informed consent patient was taken into operation theatre, 
monitors were attached, 2 large bore intravenous lines and a peripherally inserted central line was secured. An arterial line was inserted for invasive blood pressure monitoring. Patient was induced with Midazolam $0.03 \mathrm{mg} / \mathrm{kg}$, Fentanyl $2 \mu \mathrm{g} / \mathrm{kg}$, Propofol 2mg/kg and Rocuronium $1 \mathrm{mg} / \mathrm{kg}$. Depth of anesthesia was maintained using Oxygen:Nitrous oxide::50:50, Isoflurane and intravenous Dexmeditomedine infusion. Analgesia was maintained using intravenous Buprenorphine $2 \mu \mathrm{g} / \mathrm{kg}$ followed by Fentanyl $1 \mu / \mathrm{kg}$ injections at an hourly interval (3 doses given). Serial arterial blood gases were done intra operatively that were normal. The surgery lasted for 10 hours and was uneventful. After extubation patient was found to be irritable, trying to move out of neck brace and developed visual hallucinations. Hence he was shifted to ICU for post-operative monitoring. Lab reports showed hyponatraemia. ABG showed respiratory acidosis. Derangements in electrolyte and arterial blood gases were corrected. Psychiatry opinion was sought for behavioral abnormalities. History was extracted from the son that the patient had complaints of disturbed sleep from the past 3 months. Patient was started on Haloperidol $2.5 \mathrm{mg}$ and Quetiapine 25mg. Patient's condition improved and he was shifted to the ward next day. On further follow ups patient was found to be normal.

\section{Discussion}

Delirium in the postoperative period and in intensive care is an area of active research and is estimated to have high public health importance as it has greater occurrence and is preventable with pharmacological intervention.

\section{Risk Factors}

A number of risk factors have been found to be associated with post-operative delirium. They can be classified as predisposing factors and precipitating factors (Table 1).
Table 1-Risk factors for post-operative delirium

\begin{tabular}{|c|c|}
\hline Predisposing factors & Precipitating factors \\
\hline $\begin{array}{l}\text { 1. Age >65years } \\
\text { 2. Chronic cognitive decline/ } \\
\text { dementia } \\
\text { 3. Lack of sleep } \\
\text { 4. Poor vision/ hearing } \\
\text { 5. Presence of infection } \\
\text { 6. Functional dependence } \\
\text { 7. Alcohol use } \\
\text { 8. Laboratory or electrolyte } \\
\text { abnormality } \\
\text { 9. Restrain } \\
\text { 10. Severe debilitating illness } \\
\text { 11. Comorbidities }\end{array}$ & \begin{tabular}{|ll} 
1. & High risk surgical \\
& procedure \\
2. & Longer ICU* stay \\
3. & Poorly controlled \\
& pain \\
4. & $\begin{array}{l}\text { Exposure to high } \\
\text { dose opiates }\end{array}$
\end{tabular} \\
\hline
\end{tabular}

*ICU- intensive care unit

\section{Pathophysiology}

The pathophysiology remains obscure and is multifactorial. Many hypothetical mechanisms have been proposed such as disordered neurotransmission, inflammation and stress.

Evidence supports the role of reduced cholinergic transmission or excessive dopaminergic tone in delirium. $^{(4)}$

Proinflammatory cytokines such as tumor necrosis factor- $\alpha$ or interleukin-1 have also been implicated. ${ }^{(5)}$

The aging brain exhibits both quantitative and qualitative changes in neuronal circuitry that could account for the greater sensitivity of elder patients to delirium. ${ }^{(6)}$

\section{Diagnosis}

Bedside tests devised to diagnose this condition include Confusion Assessment Method $^{(7)}$ which is a commonly used tool. It has sensitivity of $93 \%$ to $100 \%$, a specificity of $98 \%$ to $100 \%$, and high interrater reliability $(\kappa=0.96)$ in the detection of delirium. ${ }^{(8)}$ It combines assessment of patient's sedation or level of consciousness with an evaluation of mental status, inattention, disorganized thinking and an altered level of consciousness. $^{(9)}$ (Table 2) 


\section{Table 2: CAM}

The diagnosis of delirium by CAM requires the presence of BOTH features A and B AND the presence of EITHER feature C or D C A M (Confusion Assessment Method)

\begin{tabular}{|c|c|}
\hline $\begin{array}{l}\text { A. Acute onset } \\
\text { and } \\
\text { Fluctuating course }\end{array}$ & $\begin{array}{l}\text { Is there evidence of an acute change in mental } \\
\text { status from patient baseline? } \\
\text { Does the abnormal behavior: } \\
\text { - come and go? } \\
\text { - fluctuate during the day? } \\
\text { - increase/decrease in severity? }\end{array}$ \\
\hline B. Inattention & $\begin{array}{l}\text { Does the patient: } \\
\text { - have difficulty focusing attention? } \\
\text { - become easily distracted? } \\
\text { - have difficulty keeping track of what } \\
\text { is said? }\end{array}$ \\
\hline $\begin{array}{l}\text { C. Disorganized } \\
\text { thinking }\end{array}$ & $\begin{array}{l}\text { Is the patient's thinking } \\
-\quad \text { disorganized, incoherent } \\
-\quad \text { unpredictable switching of subjects? } \\
\text { - unclear or illogical flow of ideas? }\end{array}$ \\
\hline $\begin{array}{l}\text { D. Alter } \\
\text { consciol }\end{array}$ & $\begin{array}{l}\text { Overall, what is the patient's level of } \\
\text { consciousness: } \\
\text { - alert (normal) } \\
\text { - vigilant (hyper-alert) } \\
\text { - lethargic (drowsy but easily roused) } \\
\text { - stuporous (difficult to rouse) } \\
\text { - comatose (unarousable) }\end{array}$ \\
\hline
\end{tabular}

*Ely EW et al Delirium in Mechanically Ventilated Patients Validity and Reliability of the Confusion Assessment Method for the Intensive Care Unit

Mini Mental State Exam is another tool that measures orientation, attention, calculation, recall and language. ${ }^{(9)}$ (Table 3)

Table 3 Mini Mental State Exam

\begin{tabular}{|l|c|}
\hline Category & Points \\
\hline Orientation to time & 5 \\
\hline Orientation to place & 5 \\
\hline Registration & 3 \\
\hline Attention and calculation & 5 \\
\hline Recall & 3 \\
\hline Language & 2 \\
\hline Repetition & 1 \\
\hline Complex commands & 6 \\
\hline $\begin{array}{l}\text { Any score greater than or equal to 24 points (out of 30) } \\
\text { indicates a normal cognition. Below this, scores can indicate } \\
\text { severe ( } \leq 9 \text { points), moderate (10-18 points) or mild (19-23 } \\
\text { points) cognitive impairment }\end{array}$ \\
\hline
\end{tabular}

Other bedside assessment methods are Geriatric Mental State Exam ${ }^{(10)}$ and Clifton Assessment Procedures for the Elderly. ${ }^{(11)}$

\section{Treatment}

The treatment of post-operative delirium includes both preventive measures and pharmacologic treatment. Prevention of delirium should begin pre operatively. It should include identification of risk factors and implementation of preventive measures.

The following preventive measures should be adopted:

1) Orientation towards care givers and surroundings 2) Uninterrupted night time sleep. 3) Visual and hearing aids 4) Intra operatively hemodynamic stability has to be maintained, hypoxia, acid base and electrolyte imbalances avoided and appropriate drug dosages should be administered 5) Early removal of Foley's catheter or other sources of infectionintravenous lines 6)Early mobilization7) Treatment of electrolyte imbalances and maintaining euvolaemia.

\section{Pharmacologic Therapy}

Neuroleptic agents, particularly haloperidol, are the medication of choice to treat delirium.

An initial dose of 1 to $2 \mathrm{mg}$ is recommended with doses of 0.25 to $0.5 \mathrm{mg}$ every 4 hours for mainten ance. $^{(12)}$

Our patient exhibited the following risk factorsold age, hearing deficit, presence of comorbidities, lack of sleep, alcohol dependence and long duration of surgery. All these could have contributed to the development of post-operative delirium.

\section{Emergence delirium vs post op delirium}

Emergence agitation or delirium might be thought of as a subset of substance-induced delirium. It has been extensively studied and is more commonin paediatric patients. It has been correlated with general anaesthesia and usually resolves without sequelae. It is associated with preoperative anxiety and responds to behavioural preparation and preoperative sedation. In a study by Lepouse et al they found that preoperative benzodiazepines, breast and abdominal surgery and surgery of long duration are risk factors for emergence delirium. ${ }^{(13)}$

In this review, we are interested in delirium that occurs after a relatively normal emergence and that occurs at some interval after surgery and 
anaesthesia. But in our patient abnormal emergence points towards emergence delirium. However the age group is more in favour of postoperative delirium and the response to treatment supports this.

\section{Conclusion}

Studies in India about post-operative delirium are only a handful. With an increase in ageing population, post op delirium no longer remains a concern only for the developed nations. Early detection and treatment will help decrease mortality and morbidity. Health care personals must be trained in this direction as "The eye sees what the mind knows".

\section{References}

1. Robinson $\mathrm{TN}$ and Eiseman B. Postoperative delirium in the elderly: diagnosis and management. Clin Interv Aging. 2008 Jun; 3(2): 351-355.

2. Dasgupta M, Dumbrell AC. Preoperative risk assessment for delirium after noncardiac surgery: a systematic review. J Am Geriatr Soc. 2006;54:1578-89.

3. Zeeshan Shaikh, Record 35 per cent jump pushes 60-plus population in India to an all-time high Indian Express April 22nd 2016

4. Jean Mantz, Hugh C. Hemmings, Jacques Boddaert, Case Scenario: Postoperative Delirium in Elderly Surgical Patients. Anesthesiology 1 2010;112:189-195

5. Bunavendran A, Kroin JS, Berger RA, Hallab NJ, Saha C, Negrescu C, et al, Upregulation of prostaglandin E2 and interleukins in the central nervous system and peripheral tissue during and after surgery in humans. Anesthesiology 2006; 104:403-10

6. Buckner RL: Memory and executive function in aging and AD: Multiple factors that cause decline and reserve factors that compensate. Neuron 2004; 44:195-208
7. Dr. Edward R. Marcantonio. Postoperative Delirium A 76-Year-Old Woman With Delirium Following Surgery JAMA. 2012 Jul 4; 308(1): 73-81.

8. Ely EW, Inouye SK, Bernard GR , Gordon S, Francis J, et al. Delirium in Mechanically Ventilated Patients Validity and Reliability of the Confusion Assessment Method for the Intensive Care Unit (CAM-ICU) JAMA. 2001;286 (21):2703-10.

9. Folstein MF, Folstein SE, McHugh PR. "Mini-mental state". A practical method for grading the cognitive state of patients for the clinician. J Psychiatr Res. 1975;12:189-98.

10. Duckworth GS. The reliability of G.E.M.S. Proceedings of the Ontario Psychogeriatric Association, September 1976:54-9.

11. Pattie AH. A survey version of the Clifton Assessment Procedures for the Elderly (CAPE). Br J Clin Psychol 1981;20:173-8.

12. Trzepacz P, Breitbart W, Franklin J, et al. Practice guideline for the treatment of patients with delirium. American Psychiatric Association. Am J Psychiatry. 1999;156:1-20

13. Lepouse C, Lautner A, Liu L, Gomis P, Leon A. Emergence delirium in adults in the post- anesthesia care unit. Br.J Anaesth 2006;96:747-53. 